\title{
Los medios de comunicación en la sociedad actual: crisis, negocio y politización
}

institucionales.us.es/ambitos/

\section{Xosé Soengas Pérez}

Universidad de Santiago de Compostela

jose.soengas@usc.es

Los medios de comunicación son necesarios para el desarrollo de la democracia y tienen un papel fundamental en el funcionamiento del Estado de derecho porque les corresponde ejercer de observadores permanentes de las instituciones y denunciar posibles abusos de poder. Tener acceso a la información es un derecho básico, por eso una sociedad libre necesita una prensa independiente que permita a los ciudadanos conocer en todo momento lo que sucede en su entorno para actuar en consecuencia. Los medios de comunicación siempre han tenido gran influencia en la sociedad, pero también hay que relativizar su poder porque están condicionados por una serie de factores, políticos y económicos, que limitan su independencia, restringen sus funciones y los hacen vulnerables.

Los vínculos entre el periodismo, la política y la economía son históricos, pero las relaciones entre los tres sectores han sido siempre interesadas $y$, con frecuencia, la prensa se ha convertido en aliada de partidos políticos y de grupos económicos, algo incompatible con un discurso crítico y con una

ÁMBITOS 2018 $n=40$ información independiente.

Los medios son poderosos porque tienen capacidad para llegar a todos los ciudadanos e influir en la sociedad. A través de su línea editorial pueden orientar la opinión pública y modificar conductas y comportamientos. Estos efectos son especialmente relevantes en periodos electorales porque se traducen en votos, por eso los políticos están interesados en controlar los medios de comunicación porque saben que son un instrumento fundamental para hacer llegar sus mensajes a la audiencia y convencerla. Y cuando los medios no ejercen como contrapeso del poder se transforman en aparatos de propaganda.

Durante la década de los 90, coincidiendo con un momento de prosperidad económica, y aprovechando una coyuntura favorable, la mayoría de las empresas de comunicación, impulsadas por una ambición desmesurada, ampliaron su negocio con proyectos poco sólidos que luego generaron grandes pérdidas y regulaciones de empleo drásticas. Su objetivo principal era la rentabilidad inmediata, por encima del interés informativo, y los grandes sacrificados fueron los contenidos. La espectacularización de la información y la banalización se impusieron para satisfacer las dictaduras de los índices de audiencia, que condicionaron de una forma determinante la selección temática y el enfoque de las 
noticias. En este contexto se priorizaron temas que garantizaban audiencias elevadas y se descuidaron las necesidades informativas de las minorías. Y, además, muchos medios de comunicación públicos asumieron criterios y objetivos propios de los privados.

En esta etapa de expansión se crearon muchos medios por oportunismo, impulsados por instituciones y organismos públicos para utilizarlos luego como altavoces de sus mensajes y así disponer de una infraestructura mediática afín durante los periodos electorales. Pero el aumento de cabeceras no supuso mayor diversidad en la oferta, ni más pluralidad informativa. Al contrario, se reforzaron los mensajes dominantes, llegando a producir una saturación en la audiencia. Al mismo tiempo, se produjo una gran concentración de medios, favoreciendo la posibilidad de establecer consensos a gran escala para fijar líneas editoriales con una ideología concreta e inculcar determinados valores a los ciudadanos.

Los principales grupos mediáticos se hicieron con el control de la información y de la opinión pública, gracias a una estructura perfectamente diversificada con capacidad para llegar a todas las audiencias y, en muchos casos, controlada por multinacionales. La pertenencia de la mayoría de los medios a grandes grupos de comunicación, algunos extranjeros, los ha convertido en empresas periodísticas sin identidad porque al integrarse en una superestructura diseñada por inversores, donde se busca la rentabilidad por encima de todo, a los medios les queda poco margen de libertad para mantener una línea editorial coherente y adaptada a las necesidades informativas de su entorno.

Los medios de comunicación siempre han estado sometidos a cambios permanentes, impulsados por la evolución tecnológica y por la necesidad de tener cada vez más influencia en la sociedad y obtener mayor rentabilidad. La informatización de las redacciones, primero, y la digitalización, después, modificaron el panorama mediático. La prensa, la radio y la televisión tuvieron que adaptarse a un escenario nuevo porque Internet y las redes sociales crearon un contexto con unas exigencias muy concretas y unos retos difíciles de asumir para muchos medios, acostumbrados a funcionar con unas estructuras tradicionales consolidadas. Internet y las redes sociales cambiaron completamente los parámetros informativos y comunicativos, y la digitalización de los medios obligó a renovar muchos protocolos para adaptarlos a los nuevos procesos de producción de la información, que exigían nuevos perfiles profesionales, nuevos conocimientos y nuevos códigos narrativos. Estos cambios también afectaron a la audiencia porque cambiaron las formas de acceso a los contenidos y de consumo de la información, algo que obligó a replantearse el concepto de competencia e incluso el concepto de actualidad y ofertar contenidos especializados para cubrir las necesidades informativas. Adaptarse al nuevo escenario supuso un esfuerzo extraordinario que muchos medios no consiguieron superar porque implicaba una serie de transformaciones que afectaban a las estructuras clásicas, a los procesos y a los protocolos de trabajo.

Hasta la llegada de Internet la competencia estaba perfectamente identificada porque cada soporte, incluso cada medio, tenía una identidad, un público específico y una audiencia estable, pero ahora la competencia llega desde otros circuitos que ya no están ubicados en un ámbito geográfico concreto. Internet y las redes sociales no tienen límites territoriales y la competencia puede estar en soportes diferentes, gracias al proceso de hibridación de medios. Además, las redes sociales permiten a los ciudadanos acceder a todo tipo de fuentes y conocer detalles e informaciones que ocultan algunos medios, interesados en 
transmitir una verdad oficial que no coincide siempre con la realidad. Y el concepto tradicional de actualidad también quedó desfasado porque la tecnología permite una renovación constante y permanente, casi instantánea, de los contenidos. Al mismo tiempo, los ciudadanos están más informados y son más críticos, por eso los medios necesitan recursos y mecanismos para dar respuesta inmediata a todas las exigencias y satisfacer las necesidades informativas de una audiencia cada vez más segmentada.

Gracias a Internet y a las redes sociales se democratizó el acceso a la información, pero también se creó una brecha importante, generando, en la práctica, dos categorías de ciudadanos, los conectados y los desconectados. La informatización de las redacciones y la digitalización de los medios también tienen luces y sombras. La mayoría de los medios optaron por afrontar los cambios estructurales que exigía el nuevo escenario mediático, conscientes del riesgo que asumían al endeudarse por encima de sus posibilidades, comprometiendo así el futuro de la empresa.

Las relaciones de los medios con el poder político y económico han existido siempre, por interés mutuo, pero con la llegada de la crisis se rompió el equilibrio aparente que mantenían. A partir de 2008 los medios entraron en una etapa delicada que duró varios años y el poder aprovechó la coyuntura para intervenir en las líneas editoriales. La situación crítica en la que se han visto muchas empresas de comunicación, motivada por el descenso de las ventas (con Internet disminuyó el consumo de prensa en papel), el aumento de la competencia, la caída de los ingresos publicitarios y las deudas generadas por las inversiones millonarias realizadas años atrás, las obligó a aceptar ayudas públicas de la Administración para sobrevivir, otorgadas bajo unas condiciones implícitas durísimas que se traducían en adaptar la línea editorial a los intereses de entidades, organismos e instituciones colaboradores. En este contexto de dependencia, los medios perdieron libertad e identidad porque se integraron en un sistema de mercado cuyos objetivos son incompatibles con los valores y con las exigencias propias del periodismo. El pluralismo, la independencia, el rigor, la calidad de los contenidos y las condiciones profesionales y laborales de los periodistas han sido los grandes perdedores en un escenario diseñado conjuntamente por el poder político y económico para favorecer sus intereses.

\section{BREVE SEMBLANZA DEL AUTOR:}

Xosé Soengas Pérez es catedrático de Comunicación Audiovisual en el Departamento de Ciencias de la Comunicación de la Universidad de Santiago de Compostela. Sus investigaciones están centradas en el análisis de los contenidos informativos de radio y de televisión.

Ámbitos. Revista Internacional de Comunicación, n.40, edición de primavera, 2018. 